Original Article

\title{
Effects of different sitting positions on skin temperature of the lower extremity
}

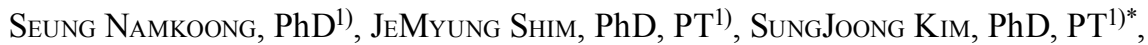 \\ JungMro Shim, PhD, $\mathrm{PT}^{2}$ ) \\ 1) Department of Physical Therapy, Kangwon National University: 3 Hwangjo-ri, Dogye-eup, \\ Samcheok-si, Gangwon-do 245-907, Republic of Korea \\ 2) Department of Skin \& Health Care, Susung College, Republic of Korea
}

\begin{abstract}
Purpose] The purpose of this study was to identify the effect of different sitting positions on the skin temperature of the lower extremity. [Subjects] The subjects of this study were 23 healthy university students (8 males, 15 females). [Methods] Normal sitting (NS), upper leg cross (ULC) and ankle on knee (AOK) positions were conducted to measure the changes in skin temperature using digital infrared thermographic imaging (DITI). [Results] ULC upper ankle, NS upper shin, ULC upper shin and NS lower shin showed significant declines in temperature with time. [Conclusion] These finding suggest that the ULC and NS sitting positions cause decline of blood flow volume to the lower extremity resulting in decrease of temperature of the lower extremity. Especially, sitting with the legs crossed interferes with the circulation of blood flowing volume much more than just sitting in a chair. Key words: Sitting position, Skin temperature, Blood flow
\end{abstract}

(This article was submitted Apr. 21, 2015, and was accepted May 18, 2015)

\section{INTRODUCTION}

With recent rapid economic growth, an affluent diet, lack of exercise, professional jobs, and a sedentary life-style in which people are usually standing or sitting for long hours, is on the rise ${ }^{1)}$. Also, as people spend more and more time using computers at home and in the workplace, thanks to the popularization of the PC and universal usage of computers at work, hours of sedentary work are increasing ${ }^{2}$.

Crossing the legs can cause hip adduction, provide stability to the sacroiliac joint ${ }^{3)}$, and increase the torque on the lumbar region by rotating the pelvis of a person with a limited joint range of motion in the coxa ${ }^{4}$. It has been reported that when working in a standing position, an asymmetrical weight supporting stand-up position causes asymmetric activation of the left and right trunk muscles and the muscles surrounding of the hip joint, imposing abnormal stress on the tissue surrounding the hip joint and sacroiliac joint ${ }^{5}$. Also, the habit of sitting with crossed legs can cause kyphosis, with the additional possibility of causing scoliosis ${ }^{6}$. Minimal stimulus following a postural change elicits a change in the peripheral circulation ${ }^{7)}$. Sitting with the legs crossed has the same impact on the nuclei and peripheral blood pressures, temporarily causing partial numbness with a stinging tingly

\section{*Corresponding author. SungJoong Kim (E-mail:} lymphkim@kangwon.ac.kr)

C2015 The Society of Physical Therapy Science. Published by IPEC Inc. This is an open-access article distributed under the terms of the Creative Commons Attribution Non-Commercial No Derivatives (by-ncnd) License $<$ http://creativecommons.org/licenses/by-nc-nd/3.0/>. feeling, as if pricked by pins and needles, due to neural pressure or blockage of blood supply ${ }^{8}$.

If the peripheral circulation does not function smoothly, the tissue or cells are not provided with sufficient oxygen, causing organic change ${ }^{9)}$.

The skin temperature is associated with the change of blood flow rate, and the skin's absolute temperature is known to vary depending on the temperature of the external environment, time, and the measured part. The controlling factor of skin temperature is blood flow rate, and a lot of blood vessels and nerves are concentrated in the skin of the body, playing a pivotal role in controlling the body temperature of the extremities ${ }^{10}$. Consequently, it is thought that sitting upright or with the leg crossed for a long time causes a temporary disturbance in the blood circulation, which will have significant impacts on the lower extremities.

A number of studies have been conducted focusing on the asymmetric muscle activities of truncal muscles during sitting with crossed legs ${ }^{11,12)}$, the legs on the spinal kinematical changes and pelvic inclination in the sitting position with the legs crossed ${ }^{6)}$, but no research has measured the change in the blood flow rate in the lower extremities through the change in skin temperature in the sitting position with the legs crossed.

Accordingly, this study was conducted to test the hypothesis that if the sitting position with crossed legs were to be continued, it would lead to neurothlipsis and blockage of the blood supply to the lower extremities, causing leg numbness and poor blood circulation. Infra-red computer thermography was used to measure the change in blood flow rate and the variation of skin temperature in the lower extremities over the course of time. 


\section{SUBJECTS AND METHODS}

The subjects of this research were healthy adults who habitually adopted a posture of sitting with their legs crossed. They were 23 healthy university students ( 8 males, 15 females) who voluntarily agreed to participate in the experiment after receiving a full explanation of the purpose and methods of research. Because this experiment required the adoption of a position of sitting with the legs crossed for a long time, the subjects were selected from among persons without peripheral vascular diseases or blood circulation disorders. The average age of the subjects was $19.48 \pm 0.80$ years, their average height was $166.98 \pm 3.16 \mathrm{~mm}$, and their average weight was $64.02 \pm 5.13 \mathrm{~kg}$. The subjects had sufficient muscular strength to perform the experiment and had no problems with the joint motion range of the coxa. Those who had congenital deformity in the lower extremities, or those who suffered serious surgical or neurological disorder, or who had a physical injury in the nether extremities, felt pain in the feet or waist over the past six months, were excluded. All test protocols were approved by the ethics committee of the Physical Therapy Faculty of Kangwon National University.

In order to estimate the change in the blood flow rate in the lower extremities, a thermograph (IRIS-XP, medi-core, South Korea) which senses the fine infrared light emitted from the body surface and it as a map of body heat was used. DITI (digital infrared thermographic imaging) analyzes infrared thermal images. It is a visual measuring method which senses the infrared light naturally emitted from the body with a highly sensitive sensor, in order to measure the temperature on the body surface. The data is recorded and analyzed on a computer to calculate the subtle changes in temperature around painful or diseased body parts. It draws a contour map of body heat in a full-color image, in order to diagnose a bodily disease.

The skin temperature is affected externally by the atmospheric temperature, humidity, air current, etc., and internally by the skin blood flow rate (5-6 $\mathrm{mm}$ depth). Skin temperature is usually in the range of $24-34{ }^{\circ} \mathrm{C}$ when the external temperature is steady at $21^{\circ} \mathrm{C}$, and it is mainly controlled by the vasomotion. Thus, skin temperature under normal conditions shows bilateral symmetry in the temperature distribution, but when a blood vessel is constrained before vasomotion, it shows an asymmetrical temperature distribution. Skin temperature, which is the surface temperature surrounding a deep part, is regulated by the vasomotion of skin, and it is used as an index to indicate the blood flow rate $^{13)}$. Before examining the shift in the blood flow rate, the study procedures and precautions were explained to the subjects before the measurements, and the changes in skin temperature were measured over time at specific sites, while the subjects maintained sitting position with their legs crossed.

The experimental procedure was as follows. For accurate imaging, the range of the indoor temperature for each experiment was kept within $20-21^{\circ} \mathrm{C}$, the subjects were given 20 minutes to adapt to the laboratory conditions. Before the test, subjects were given sufficient information about the factors affecting infrared images, and sunbathing was prohibited for one week before the experiment. Electromyography (EMG),
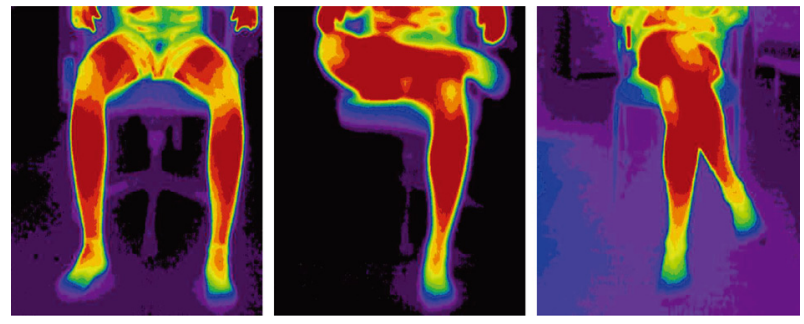

Fig. 1. Digital infrared thermographic images of each position. A. Normal sitting, B. Ankle on knee, C. Upper leg cross

nerve block, acupuncture, body manipulation, and massage were prohibited within 72 hours before the test; and alcohol consumption, smoking, physical therapy, and transcutaneous electrical nerve stimulation (TENS) were prohibited within 24 hours before the test ${ }^{14)}$.

The chair used in the experiment had a backrest and armrest, adjustable height, and was fixed to the floor. The height of chair was adjusted so that in the upright sitting position the hip joint and knee joint formed angles of 90 degrees. Subject wore shorts to expose the legs for measurement. Taking into consideration the physical fatigue caused by the experimental tasks, subjects were divided into a group of 12 persons (group A) who first adopted a sitting position with the legs crossed, the lower part of the thigh of one leg touching the upper part of the thigh of the other leg (upper leg cross; ULC) and a group of 11 persons (group B) who first adopted a position with one ankle placed on the opposite knee (ankle on knee; AOK). The two other sitting postures were adopted in a random order in both groups A and B (Fig. 1). The subjects were instructed to adopt as comfortable posture as possible so that they could sustain that posture, and they were continuously advised not to excessively lean on the chair's backrest. They were also asked to adopt a position in which their knee, shin, and instep were clearly seen on the monitor. Each posture was kept for 30 minutes, and each posture was photographed a total of 4 times, at $0 \mathrm{~min}, 10 \mathrm{~min}, 20 \mathrm{~min}$, and $30 \mathrm{~min}$. Between each posture measurement, subjects were given a 10 min break to allow their bodies to return to the original body temperature, and during the break, an ankle pumping exercise was executed while sitting on the floor with the legs stretched.

On the assumption that in the upright sitting position the temperature in the both legs are symmetrical because subjects are healthy adults, only one leg which is raised upward was measured. The crossed legs were measured on the both sides to compare between them. The measurement sites were the knee (patella), shin (at the midway point of the shin bone), top of the foot (midway along the third metatarsal). The tip of the toe showed the biggest temperature change, but it was omitted for convenience of measurement because of subjects with obscure toe tips. Among the 32 constituent parts, it is said that the average temperature difference is $0.24{ }^{\circ} \mathrm{C}^{15)}$, so if at least $0.5-0.7^{\circ} \mathrm{C}$ difference is found in the symmetrical comparison, it should be generally evaluated as significant ${ }^{16)}$.

A repeated one-way ANOVA determine the significance of temperature differences between the upright sitting po- 
sition and sitting with the legs crossed position. Scheffe's test was conducted as a post hoc test to determine the significance of differences. Statistical analysis was performed using SPSS 21.0, and a significance level of 0.05.

\section{RESULTS}

The results are shown in Table 1. A significant drop in temperature was found with the course of time in the ULC upper ankle, NS upper shin, ULC upper shin, and the NS lower upper shin positions $(\mathrm{p}<0.05)$. There were no statistically significant changes in the other measured body parts, but a clear difference in temperature was found in a temperature transition by posture with the course of time.

\section{DISCUSSION}

There has been little research of contemporary subjects' sitting position with the legs crossed, and the research that has been performed has focused on the spinal angle, abdominal muscles, and activity of the psoas muscles.

Even though previous studies have always emphasized the importance of an upright sitting position, contemporary subjects who work on computers or study for long hours tend to adopt a posture that strays from normal alignment to reduce fatigue in the postural muscles. Also, crossing the legs causes hip adduction, which provides stability to sacroiliac joint ${ }^{12)}$, and reduces the muscle activities of the internal and external obliques. It is a posture which is often adopted to reduce fatigue in the abdominal muscles during long hours of work. On the other hand, sitting with the legs crossed can also increase lumbar region torque by rotating the pelvis of a subject with a limited joint motion range of a coxa ${ }^{4}$. It causes axial asymmetry with asymmetrical activation of the internal obliques on both sides, and the posture of sitting with the legs crossed for a long time may also cause cyanosis and scoliosis ${ }^{6}$. If the peripheral circulation does not function smoothly, the tissues or cells are starved of oxygen, resulting in organic change, but minimal stimulus following a posture change elicits a change in the peripheral circulation ${ }^{5,7)}$.

Sitting with the leg crossed has the same impacts on the nuclei and peripheral blood pressures, temporarily causing partial numbness with a stinging/tingly feeling as if pricked by pins and needles, due to neural pressure or blockage of blood supply ${ }^{8)}$.

The controlling factor of skin temperature is blood flow rate, and a lot of blood vessels and nerves are concentrated in the skin of body, playing a pivotal role in controlling the body temperature in the extremities ${ }^{10)}$. Accordingly, this study measured the change in blood flow rate based on the change of temperature in an upright sitting position and in a sitting position with the legs crossed over the course of time, and discussed the results. The temperature of the lower extremities decreased in the three postures adopted in this study. This is in agreement with a previous report that found that sitting without moving the legs for a long time decreases the circulation in the lower extremities ${ }^{17}$. A significant drop in temperature was found over the course of time in the ULC position. This result may be explained by different compression forces in the two crossed-leg positions. Compression
Table 1. The changes in temperature of the lower extremity $\left(\mathrm{n}=23\right.$, unit: $\left.{ }^{\circ} \mathrm{C}\right)$

\begin{tabular}{lccccc}
\hline & & 0 & 10 & 20 & 30 \\
\hline U- & NS & $27.3 \pm 0.6$ & $27.1 \pm 0.7$ & $26.7 \pm 0.8$ & $26.3 \pm 0.2$ \\
ankle & ULC & $27.2 \pm 0.7$ & $26.7 \pm 0.7$ & $26.1 \pm 0.8$ & $25.6 \pm 0.8^{*}$ \\
& AOK & $27.5 \pm 0.9$ & $27.2 \pm 1.1$ & $26.7 \pm 1.0$ & $26.1 \pm 1.1$ \\
U- & NS & $29.6 \pm 0.4$ & $29.3 \pm 0.4$ & $29.0 \pm 0.4$ & $28.6 \pm 0.3^{*}$ \\
shin & ULC & $27.3 \pm 0.7$ & $26.8 \pm 0.8$ & $26.2 \pm 0.8$ & $25.7 \pm 0.8^{*}$ \\
& AOK & $27.3 \pm 1.1$ & $27.3 \pm 1.2$ & $26.9 \pm 1.2$ & $26.4 \pm 1.2$ \\
U- & NS & $27.8 \pm 0.4$ & $27.7 \pm 0.4$ & $27.5 \pm 0.4$ & $27.2 \pm 0.4$ \\
knee & ULC & $28.0 \pm 1.0$ & $28.1 \pm 1.0$ & $27.8 \pm 0.9$ & $27.6 \pm 1.0$ \\
& AOK & $27.2 \pm 0.9$ & $27.0 \pm 0.8$ & $26.6 \pm 0.7$ & $26.5 \pm 0.7$ \\
L- & NS & $27.3 \pm 0.6$ & $27.1 \pm 0.7$ & $26.7 \pm 0.8$ & $26.3 \pm 0.2$ \\
ankle & ULC & $27.6 \pm 0.7$ & $27.5 \pm 1.0$ & $27.0 \pm 0.9$ & $26.5 \pm 1.0$ \\
& AOK & $27.9 \pm 0.7$ & $27.5 \pm 0.8$ & $27.1 \pm 0.8$ & $26.4 \pm 0.8$ \\
L- & NS & $29.6 \pm 0.4$ & $29.3 \pm 0.4$ & $29.0 \pm 0.4$ & $28.6 \pm 0.3 *$ \\
shin & ULC & $28.9 \pm 1.0$ & $28.6 \pm 0.8$ & $28.3 \pm 0.7$ & $28.0 \pm 0.7$ \\
& AOK & $28.9 \pm 0.7$ & $28.8 \pm 0.7$ & $28.4 \pm 0.6$ & $28.1 \pm 0.7$ \\
& NS & $27.8 \pm 0.4$ & $27.7 \pm 0.4$ & $27.5 \pm 0.4$ & $27.2 \pm 0.4$ \\
L- & ULC & $27.3 \pm 0.6$ & $27.1 \pm 0.6$ & $26.9 \pm 0.6$ & $26.9 \pm 0.6$ \\
knee & AOK & $27.0 \pm 0.6$ & $26.9 \pm 0.5$ & $26.7 \pm 0.5$ & $26.6 \pm 0.4$ \\
\hline
\end{tabular}

NS: Normal sitting, ULC: Upper leg cross, AOK: Ankle on knee. $* \mathrm{p}<0.05$

force on the femoral vein in the ULC position is stronger than in the AOK position, causing problems with venous return from the distal lower extremity.

An earlier study found that, subtle voluntary movement does not cause a significant decrease in the surface vein pressure in legs ${ }^{18)}$. This is significant in that a subtle voluntary movement is related to a $50 \%$ decrease in foot edema compared to a static sitting position ${ }^{19)}$. In a sitting position, voluntary foot movement prevents a drop in the skin surface temperature, and it is recommended to do leg exercises frequently and voluntarily during long hours of sitting at work $^{20)}$.

This study performed basic research into the estimation of the blood circulation in multiple sitting positions using infrared computer thermography (IRCT).

The subjects were in their twenties, and they had no perspiration in the extremities or circulation disorders. Nevertheless, they showed a decrease in the temperature in the lower extremities and started to suffer dysesthesia in the sitting position from 10 minutes after the start of experiment. This result has a clinically significant implication for the elderly, diabetics, and patients with peripheral vascular diseases. The leg numbness recorded in this study supports the result of a previous study that reported that leg numbness is caused by neurothlipsis or blockage in the blood supply ${ }^{8)}$.

Diabetic patients have a limited blood flow rate to the lower extremities, and diabetic patients are 3-4 times more likely to have a peripheral vascular disease than a healthy person, and the disease tends to be more severe and caused by blood vessels ${ }^{21,22)}$. In this regard, diabetic patients and patients with a peripheral vascular disease are more likely to be affected by sitting for long periods than a healthy person. 
Disturbance in a smooth blood circulation, neurosis, infection, creation of calluses are reasons for the delay of wound-healing in diabetic patients ${ }^{23}$. Blood circulation helps metabolism, growth, and reproduction by supplying tissue cells with nutrients and oxygen. It also transports carbon dioxide and wastes generated within cells for elimination in the lungs and kidneys. Thus, blood circulation in a wounded area is vital to wound healing. The ideal temperature for injury recovery is $37^{\circ} \mathrm{C}$. If the temperature drops, phagocytic ability is decreased and cell mitosis is reduced ${ }^{24)}$ For this reason, it is our recommendation that the elderly, diabetics, and patients with a peripheral vascular disease have an injury in the extremities, they shouldl avoid sitting for long hours, and especially sitting with their legs crossed as it causes dysesthesia and poor circulation.

A previous study reported that continuous and regular muscular contraction increases blood flow slightly 25,26 . Accordingly, since contemporary work styles involve sedentary work, sedentary workers should be encouraged to sit upright, and when long hours of work is unavoidable, they should be instructed to do frequent leg exercises to facilitate blood supply. In addition, for the smooth blood circulation, they should take a break to prevent disturbance of the blood circulation in the lower extremities.

A limitation of this study was that the subjects were limited to healthy persons in their twenties, preventing a generalization of research outcomes to all age groups. Also, because of the difficulty of keeping one position for a long time, the measurement time was limited to 30 minutes. Furthermore, although efforts were made to measure precisely the same area of all participants, because of the small size of the areas being measured and the programming features of the measuring machine, subjective positioning was involved, and the area observable on the surface was limited.

IRCT estimates the blood flow over the course of time by comparing the temperatures at one point of on surface images. Future studies need to investigate subjects with a wide range of ages and clinically useful body parts other than the three areas measured in this study. An ultrasound study of direct observance of the blood flow inside blood vessels also needs to be simultaneously conducted.

\section{REFERENCES}

1) Lee JH, Kim BR, Kim BK, et al.: Effect of walking exercise on the hematocele dynamic factors in patients with venous disease. Kor J Sports Sci, 2003, 14: 495-502.

2) Li G, Haslegrave CM: Seated work postures for manual, visual and combined tasks. Ergonomics, 1999, 42: 1060-1086. [Medline] [CrossRef]

3) Snijders CJ, Slagter AH, van Strik R, et al.: Why leg crossing? The influence of common postures on abdominal muscle activity. Spine, 1995, 20 : 1989-1993. [Medline] [CrossRef]
4) Lee SW, Kim SY: Effects of hip exercises for chronic low-back pain patients with lumbar instability. J Phys Ther Sci, 2015, 27: 345-348. [Medline] [CrossRef]

5) Nam I, Shin J, Lee Y, et al.: The effect of foot position on erector spinae and gluteus maximus muscle activation during sit-to-stand performed by chronic stroke patients. J Phys Ther Sci, 2015, 27: 571-573. [Medline] [CrossRef]

6) Kang SY, Kim SH, Ahn SJ, et al.: A comparison of pelvic, spine angle and buttock pressure in various cross-legged sitting postures. Korean Res Soc Phys Ther, 2012, 19: 1-9.

7) Goetz RH: Effect of changes in posture on peripheral circulation, with special reference to skin temperature readings and the plethysmogram. Circulation, 1950, 1: 56-75. [Medline] [CrossRef]

8) van Velthoven $\mathrm{MH}$, Holewijn S, van der Wilt GJ, et al.: Does wave reflection explain the increase in blood pressure during leg crossing? Blood Press Monit, 2014, 19: 129-133. [Medline] [CrossRef]

9) Kim YH, Kim CS, Mun HY, et al.: Human Physiology. In: Circulation Physiology. Seoul: Hyunmoon Press, 2009, pp 79-93.

10) Uematsu S, Edwin DH, Jankel WR, et al.: Quantification of thermal asymmetry. Part 1: Normal values and reproducibility. J Neurosurg, 1988, 69: 552-555. [Medline] [CrossRef]

11) Park Y, Bae Y: Comparison of postures according to sitting time with the leg crossed. J Phys Ther Sci, 2014, 26: 1749-1752. [Medline] [CrossRef]

12) Snijders CJ, Slagter AH, van Strik R, et al.: Why leg crossing? The influence of common postures on abdominal muscle activity. Spine, 1995, 20: 1989-1993. [Medline] [CrossRef]

13) Thews G, Schmidt RF: Human physiology. New York: Springer-Verlag, 1983.

14) Snijders CJ, Bakker MP, Vleeming A, et al.: Oblique abdominal muscle activity in standing and in sitting on hard and soft seats. Clin Biomech (Bristol, Avon), 1995, 10: 73-78. [Medline] [CrossRef]

15) Lawson R: Implications of surface temperatures in the diagnosis of breast cancer. Can Med Assoc J, 1956, 75: 309-311. [Medline]

16) Jeong MY, Yu JS, Chung WB: Usefulness of thermography in diagnosis of complex regional pain syndrome type I after transradial coronary intervention. J Invasive Cardiol, 2013, 25: E183-E185. [Medline]

17) Beasley R, Raymond N, Hill S, et al.: eThrombosis: the 21st century variant of venous thromboembolism associated with immobility. Eur Respir J, 2003, 21: 374-376. [Medline] [CrossRef]

18) Ogiwara S: Calf Muscle pumping and Rest Positions during and/or after Whirpool Therapy. J Phys Ther Sci, 2001, 13: 99-105. [CrossRef]

19) Winkel J, Jørgensen K: Swelling of the foot, its vascular volume and systemic hemoconcentration during long-term constrained sitting. Eur J Appl Physiol Occup Physiol, 1986, 55: 162-166. [Medline] [CrossRef]

20) Winkel J, Jørgensen K: Evaluation of foot swelling and lower-limb temperatures in relation to leg activity during long-term seated office work. Ergonomics, 1986, 29: 313-328. [Medline] [CrossRef]

21) Young MJ, Veves A, Smith JV, et al.: Restoring lower limb blood flow improves conduction velocity in diabetic patients. Diabetologia, 1995, 38: 1051-1054. [Medline] [CrossRef]

22) Leoniuk J, Lukasiewicz A, Szorc M, et al.: Doppler ultrasound detection of preclinical changes in foot arteries in early stage of type 2 diabetes. Pol J Radiol, 2014, 79: 283-289. [Medline] [CrossRef]

23) Yazdanpanah L, Nasiri M, Adarvishi S: Literature review on the management of diabetic foot ulcer. World J Diabetes, 2015, 6: 37-53. [Medline] [CrossRef]

24) O'Meara S, Cullum N, Majid M, et al.: Systematic reviews of wound care management: (3) antimicrobial agents for chronic wounds; (4) diabetic foot ulceration. Health Technol Assess, 2000, 4: 1-237. [Medline]

25) Mukaida H, Matsushita S, Inotani T, et al.: Peripheral circulation evaluation with near-infrared spectroscopy in skeletal muscle during cardiopulmonary bypass. Perfusion, 2015. [Medline] [CrossRef]

26) Barcroft $\mathrm{H}$, Dornhorst AC: The blood flow through the human calf during rhythmic exercise. J Physiol, 1949, 109: 402-411. [Medline] [CrossRef] 